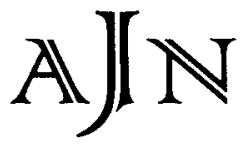

Original Article

\title{
Prevalence of renal tuberculosis among patients presenting with active pulmonary tuberculosis in Ilorin - Nigeria
}

\author{
Chijioke $\mathrm{A}$ and Aderibigbe $\mathrm{A}$
}

Department of Medicine, Renal Unit, University of llorin Teaching Hospital, Ilorin, Nigeria

\begin{abstract}
Tuberculosis (TB) is a major health problem world-wide, especially in tropical developing countries involving major organs in the body. The kidney is usually affected through haematogenous spread from a primary focus. Renal tuberculosis is the commonest form of extra pulmonary TB particularly among the Caucasians but thought to be rare in Blacks. Due to the paucity of data on the prevalence of renal TB. A prospective study was undertaken to investigate the prevalence of renal $\mathrm{TB}$ in cases of active pulmonary TB (PTB) in Ilorin - Nigeria.

Confirmed cases of active PTB patients were consecutively recruited from the Pulmonary Clinic and the PTB Ward over a one year period. The inclusion critcria were sputum acid fast baccili (AFB) posilivity on two or more occasions and radiological evidence of PTB. Patients fullfilling the above criteria were investigated by urine analysis for sterilc acid pyuria, Z-N stain, plain abdominal x-rays, renal ultrasound, intravenous urogram and renal biopsy.

A tolal of 148 active PTB patients were studied (91 males, 57 females). Male to female ratio was 3:2.

The mean age of the malcs and females with renal TB was 40 and 29 ycars respectively.

The prevalence rates of AFB in urine and sterile acid pyuria were $9.5 \%$ and $8.8 \%$ respectively. Only $2.7 \%$ had both AFB in urine and sterile pyuria.

Renal histology was abnormal in $70 \%$ of the biopsied kidneys with sterile pyuria. The combination of AFB in urine and histologic evidence of renal TB increased the prevalence of renal $\mathrm{TB}$ to $14 \%$ in the study.
\end{abstract}

Correspondence and offprint requests to: Aderibigbe A. Department of Medicine, Renal Unit, University of Ilorin Teaching Hospitat Ilorin Nigeria.
The study shows that renal TB in active PTB may be similar in Black and White populations. The diagnosis is difficult and a high index of clinical suspicion with combined diagnostic tools are required to identify the lesion.

Key words: pulmonary TB, renal tuberculosis, sterile pyuria, tuberculosis of the kidney, urinary tuberculosis,

\section{Introduction}

Tuberculosis is an infective granulomatous disease caused by many species of mycobacteria, the commonest of which is mycobacterium tuberculosis. Pulmonary disease accounts for about $60 \%$ of cases while $40 \%$ are extrapulmonary [1].

Pulmonary tuberculosis (PTB) is a major health problem World-wide, especially in tropical developing Countries where the disease is endemic $[2,3,4]$. The World Health Organization (WHO) reports showed that there are about 15-20 million cases of tuberculosis annually with more than three million yearly deaths [5].

Renal involvement in tuberculosis occurs through haematogenous spread from a primary focus with an incidence of 5\% approximately [6]. In the Western World, the commonest extra pulmonary site of tuberculosis is the kidney and occurring predominantely in men $[7,8]$. An autopsy review of renal tuberculosis (TB) found associated fibrocavitory pulmonary lesions in $78 \%$ of cases [8]. Most studies on PTB outside Nigeria have shown that $26-50 \%$ of renal TB co-existed with active PTB and 6-10\% of 
screened active PTB cases had renal involvement $[9,10,11]$.

In another autopsy study of 30 active PTB patients who had no renal symptoms, demonstrated histologically that $73 \%$ of them had bilateral renal TB [12]

Many authors in Nigeria, have shown that a significant number of extrapulmponary TB patients had PTB [13,14,15].

Osegbe found that $135 \%$ of 49 renal TB diagnosed had active PTB and their urine demonstrated sterile acid pyuria. AFB and posituve culture.

The paucity of data. gained from both clinical practice and autopsy findings. on the prevalence of renal TB in Nigeria tends to give the impression that renal $T B$ is not common $[13,14.15,16.17]$ This may be due to low diagnostic value of clinical features which are often used in the diagnosis as patients with advanced renal TB may be asymptomatic $[10.11,12.131$.

Morcover, no single investigative tool for the diagnosis of renal TB is infallible and the relance on: clinical features may be deceptive $[9,10]$ Gencrally. it is not conceivable that the kidney which is one of the highly perfused organs should be resislan* (o) tuberculosis in Nigeria wnere PTH is endemic $[4,5$, This study was done to invesugate the prevalence of renal TB in cases of actrve PTI at Ilorin where an average of $1+$ new cases with aclive PTB are sean monthly.

\section{Materials and methods}

148 patients (91 males, 57 females) with active PTB were consecutively recruited from the pulmonary clinic and PTB Kard over a one-year perod from March 1995 to February 1996. The inclusion eriersa were

1. Sputum posituve for $A F B$ onl two or inore occasions

2. Radiological evidence of PTH.

Exclusion criteria werc.

1. Diagnosed cases who had started anti-TB drugs two week prior to presentations.

2. Unwillingness to participate.

3. Those aged 15 years and belon

These patients were divided according to sex and age ( 10 years age groups). They were subjected to urne examination with specific reference to acid and alcohol-fast bacilli and sterile acid pyurıa.

All PTB patients with AFB in urine on two or more occasions with or without acid pyuria were considered to have renal TB. PTB patients with only sterile acid pyuria on two or more occasions were taken through an investigative Organogram that involved plain abdominal $\mathrm{X}$-rays, intravenous urogram (IVU) and renal biopsy under ultrasonic guidance with specific reference to features of renal TB. All patients with sterile pyuria and associated radiological evidence of renal TB (renal calcification, calyccal abnormalities, papillary necrosis, cavitary lesions and uretcric strictures) were diagnosed as renal TB

A subset of PTB pattents with persistent urinary symptoms and sterile acid pyuria had renal biopsy after a writlen consent. The inclusion critena were

1. Increased white blood cells per cubic millimetre (mm.3) ol urine.

2. Negative urine cultures for bacteria

3. Normal plan abdominal $\lambda$-rass and IVU.

The exclusion criteria were.

1 Hestory of antibiotic intake within the previous iwo necks of stud.

2. Presence of renal stones, prostatitis, pregnancy of malignancy of the urogenital traci.

3. Those on cytotoxic drugs and steroid therapy

\section{Results}

148 patients (9) males, 57 lemales, with active PTB were seen during the study period (March 1995 Fenruary 1996). The maiority in both sexes were aged between $20-40$ years (Table $11.68 \%$ of males were below 40 years of age as compared $672 \%$ in femalles

Considermes the climi ial data 43\% of dagnosed remal TB patients had uratary liequency, 36 r. had nocuria while $28.5 \%$ presented with lom pans. Hacmaturia and dysurat were uncommon ( $7 \%$ each). The only positive physical finding was renal angle lenderness in $36 \%$ of the cases ('Tabir 2).

Fourteen patients 18 lemales, 6 males were found io have $A F B$ in therr urine and th $y$ were aged berween $18-5.3$ years. Females constututed the majomy $(57 \%)$ with a mean age of 29 years Males accomned for $+3 \%$ of the cases will a mean age of 40 years (labic 3)

Thuteen out of the 148 P'B patients had only stertic pyura while four (2.7\%) had both abnomalitics in theil urme. All PTB patients with both $\mathrm{Al}$ - B in uring; and sterik pyura were females in the 3 rd and 4 (1) decades of life (Table 4 ,

Ten out of 13 PTB paticnts with only sterile acid pyuria had renal biopsy and $(70 \%)$ of them had histo pathologic evidence of renal TB. The commonest histopathologic lype observed in the biopsies was interstitial nephritis $(20 \%)$ Chronic pyelonephritis and focal segmental glomerulosclerosis accounted for $20 \%$ respectively (Table 5 ).

No abnormality was detected in all the 8 patients who had IVU. Only one patient showed hydronephrosis on renal Ultrasound (Table 1). 
Table 1. Age and sex distribution of PTB patients

\begin{tabular}{llllllll}
\hline & $10-19$ years & $20-29$ years & $30-39$ years & $40-49$ years & $50-59$ years & $60-69$ years & Total years \\
\hline Male & 7 & 35 & 20 & 13 & 14 & 2 & 91 \\
Female & 6 & 21 & 14 & 7 & 7 & 2 & 57 \\
\hline
\end{tabular}

Table 2. Clinical feattures of renal TB in the study

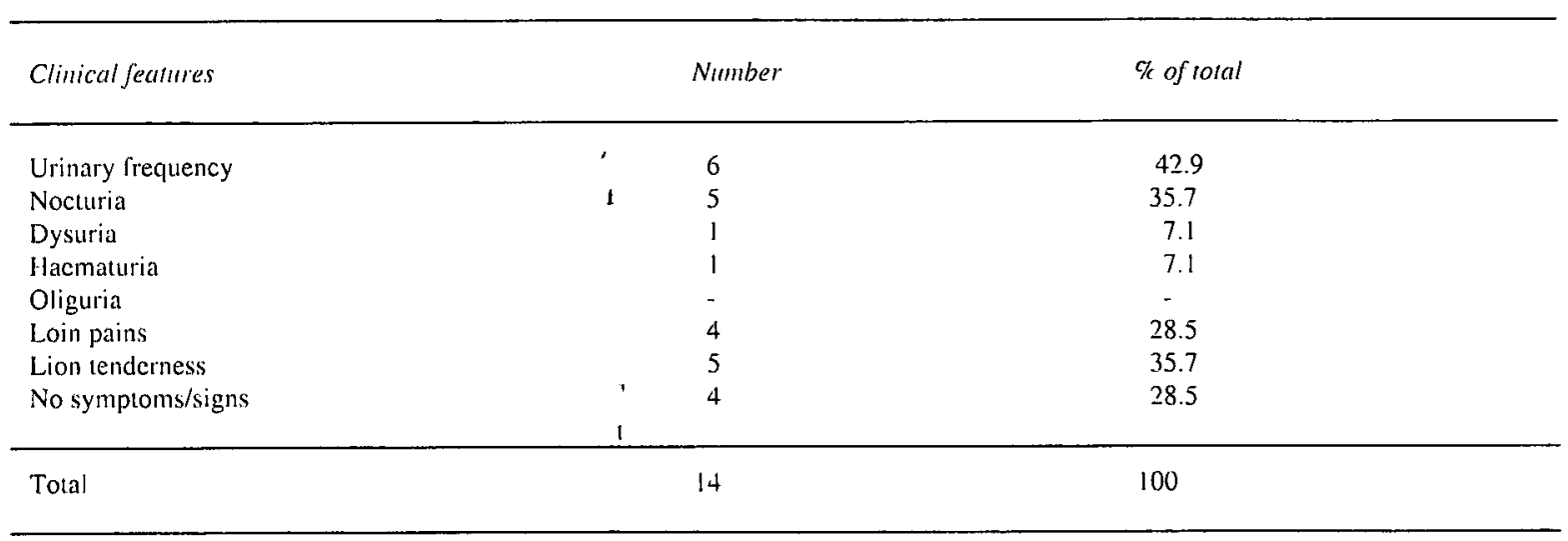

Table 3. Age and sex distribution of P'TB with AFB in urinc

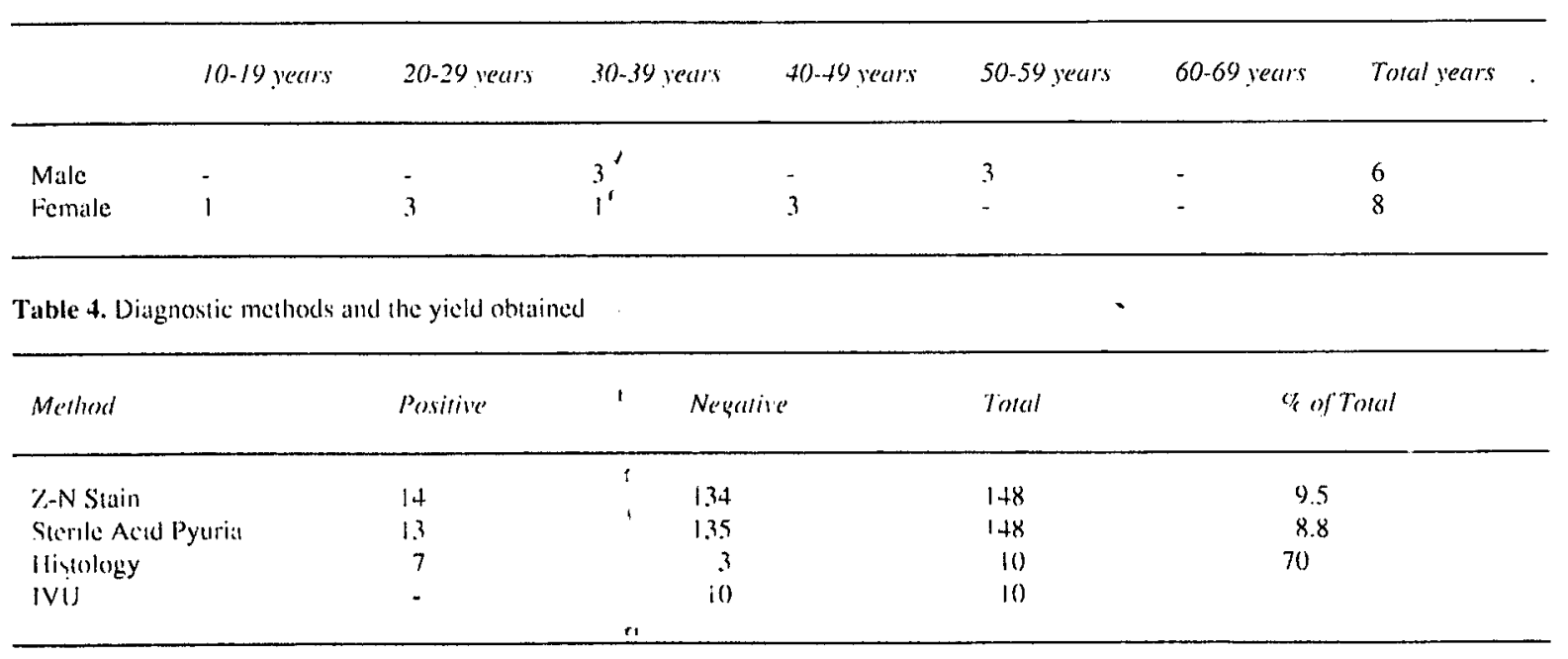

Table 5. Renal histology in the study

\begin{tabular}{|c|c|c|}
\hline Hoscology' & Vimber mesenting & Sir of tomal \\
\hline Intersutial nephrits & $\because$ & 20 \\
\hline ('hronke pyclonephritis & 1 & 10 \\
\hline Pocial cegnentat cilomesulusclerosis & 1 & 10 \\
\hline Unclissified & 3 & 30 \\
\hline Normal & $i$ & .71) \\
\hline
\end{tabular}

\section{Discussion}

The prevalence rate of $9.5 \%$ of renal $T B$ in patients with actıve PTB observed in this study lalls within the range of $6 \% 1013.5 \%$ previously reported by other investigators in active PTB populations 1 $13,18,19,20,21]$. Earlier workers both in Nigeria and Europe had reported a relatively low prevalence of 
$3.2 \%, 2.9 \%$ and $6 \%$ repectively $[14,16,19]$. Most of the earlier reports in Blacks particularly in Nigeria showed a lower prevalence of renal TB. These studies were retrospective or autopsy findings. The higher prevalence of renal TB could be explained by the study being prospective and the prompt analysis of the specimens. Osegbe in the early eighties found a similar prevalence in Lagos [13] and our findings are almost similar to those reported in Caucasians [20, $21]$.

The increase in the incidence of renal TB to $14 \%$ when combined sterile acid pyuria and positive AFB in the urine were used demonstrated the value of multiple diagnostic criteria. The higher percentage of positive renal TB histology in patients with sterile acid pyuria that were biopsied support the value of sterile acid pyuria. The higher prevalence of renal TB in this study does not support the assumption that the Caucasian kidneys are more prone to renal TB.

The occurence of Z-N AFB positve urine in $70 \%$ of the patients most of which occured in the 2 nd and 4th decades of life in this study had been earlier reported $[10,13,22]$. Renal TB tends to be rare before the age of 14 years and its rate declines after the 5 th decade of life $[8,9,10,23]$

There are conflicting reports on the relationship of sex to renal TB infection. While some workers had found a male preponderance. Others denied such difference $[10,24]$.

In our study a male: female ratio of 3:2 was found.

Renal TB can be entirely asymptomatic as observed in $29 \%$ in this study. When it becomes symptomatic, urinary frequency usually is the most reported symptom. Nocturia, lonn pain, dysuria and haematuria in that order of frequency are other symptoms that had been reported $[10,13,25]$. Thus, it is not suprising that there is a relative paucity of physical signs in this study.

The only significant physical finding was renal angle tenderness. This is consistent with earlier reports $[9,10,11,12,13]$. One of the authors found no physical signs in $63 \%$ of his cases. Generally the difficulty in early diagnosis and treatment is due to the absence of specific symproms and signs for renal tuberculosis.

Recent studies have shown that urine Z-N stain is as reliable as urine culture in the diagnosis of renal TB. A positive yield as high as $63-70 \%$ of Z-N stained AFB in urine and $2450 \%$ positive AFB culture in urine had been reported by some workers $[10,13]$. Despite the simplicity and relative sensitivity of these tests but no single method of diagnosing renal $\mathrm{TB}$ is infallable. A combination of many diagnosic techniques will yield higher positivity. IVU is not a very sensitive diagnosing tool for evaluating renal infections and normal films have been reported in $75 \%$ of patients with proven renal infections $[26,27]$ All the IVU results in this study were normal Ultrasound with high resolution probes and C-T Scan have been shown to be better radiologic diagnostic tools $[28,29]$. This study did not demonstrate the sensitivity of ultrasound in the diagnosis of renal TB as only one of the patients showed evidence of renal TB. A combination of urine tests and tissue histology may be more relevant than urine tests alone as urinary findings may originate from other parts of the urogenital system [20].

It is difficult from this study to argue for a relative resistance of the kidneys in the Nigerian African to Tuberculosis as it was previously considered as the prevalence of renal TB found was similar to those reported in Caucasians. A high index of suspicion at all times will definitely increase the diagnostic yield when combined with increased awareness of the disease, improved investigating tools. The absence of these important secondary investigating parameters may be responsible for the erroneous assumption that renal tuberculosis is not common in blacks. In view of the limited number of patients and short duration of the study a more comprehensive and well coordinated country wide study of renal involvement in active PTB in Nigeria is recommended.

\section{References}

1. Manson-Bahr PE Bell Dr. Manson s: Tropical Medicine 19th reprint Bailiere Tindall, London. Philadelphia: 987-997.

2. Schmidt J: Research towards global control and prevention of tuberculosis with emphasis on vaccine devclopment. Rev. Infect. Dis. 1989; 11. 1335.

3. Styblo K: Overview and Epidemiologic assessment of the current global tuberculosis situation with emphasis on control in developing Countries. Rep. Infect. Dis. 1989 2. 339346.

4. Osuafor K O: A 10 year retrospective sludy of pattern of tuberculosis in UNTH, Enugu Orient J. Med 1993; 5: 85-87.

5. WHO 1983. WHO Expert committee on tuberculosis. WHO Tech Rep. Ser. No 685

6. Davidson A M. Tuberculosis of the Urinary tract. Texi of Nephrology, 1st Ed. lleineman Medical Books, London 1988; 330-332.

7 Eknoyan G. Suki WN. The Kidney in systemic disease. 2nd Ed. 1981. Willy Medical Publications. John Willey and Sons: 547-549.

8 Medlar EM, Span DM and Ilolliday R: Post-mortem compared with clinical dagnosis of urinary tuberculosis. $J$. Urol 1949; 61. 1078-1088.

9. Bayu Teklu and Jonathan Ostrow Urinary tuberculosis: a review of 44 cascs treated. J. Urol 1975, 115: 507-509

10. Narayan As, Gallagher Fi, Erlaen DP, Kelly Dg and Duff EA: Renal TB. A review of 66 castes J. Irish med. Ass. 1977; 70: 83.85 .

11. Shamma NZ, Hadidy A and Al-Aslari R Siragel Dn MN. Urinary tuberculosis: An experience of Teaching Hospial in Syria. Int-urol-Nephrol. 1992, 74: 471.486.

12. Edgar $M$ and Medlat $M A$ : Cases of renal infection in pulmonary TB AM J. Path. 1927; 2: 4011-4!1

13 Osegbe DN Gento-urinary tuberculosis Nig Med. J. 1983: 13. $75-80$

14. Ogunbiyı TA and Oyeniyi $\mathrm{J} O$. Pattern of extrapulmonary TB. Nig Med. J 1975; 12:45-51

15. Lewis EA anf Abioyc AA: Tuberculosis of the abdomen: $A$ clinico pathologic review. Tubercle 1975: 56: 149-155. 
16. Alausa KO, Osoba AO, Montefiore D and Sogbetun OA: Laboratory diagnosis of tuberculosis in developing countries. Afri J. Med. Sci: 1977; 6: 103-108.17.

17. Kolawole TM: Tuberculous Ileocolitis in Ibadan: A clinical pathologic review. Gut 1972; 5: 524-526.

18. Brown L: Tubercle bacilluria in urine JAMA 1915; 14: 886890.

19. Hobb FB: The elimination of tubercle bacilli by the kidney in PTB. Tubercle 1923; 5: 105.

20. Cunningham JH: Facts regarding the relation of tuberculosis of the kidney to the TB of the lungs. Boston. Med. Surg. J. 1911; 165: 872.

21. Bentz RR, Dimchaff DG, Nimefoff $M$, Isang $A$ and Weg JG: The incidence of urine culture positive for mycobacterium tuberculosis in general tuberculosis patient population. Am. Rev. Resp. Dis 1973; 11: 647-650.

22. Gow JG: The changing pattern of renal TB. Brit. J. Urol 1976; 42: 655-657.
23. Borthwick WM: Present position of urinary TB. Brit J. Urol 1970; 42: 642-646.

24. Bruce LG: Incidence of genito-urinary $\mathrm{TB}$ in Western Scotland. Brit J. Urol 1970; 42: 637-641

25. Cooper HG and Robinson EG: Treatment of genito-urinary TB; Report after 24 years. J. Urol 1972; 108: 136-142.

26. Hoddick W and Jeffrey RB et al : C-T Scan and sonagraphy of severe renal and perirenal infections. Ann. J. Rad. 1983; 140 517.

27. Wicks J. D. and Thornbury JR: Acute renal infections in Adults. Rad Clin. North Am. 1979; 17: 245.

28. Porpiglia F, Morra I, Rocca A and Foutana D: Echographic aspects of renal tuberculosis. Arch. Ital. Urol. Androl. 1996; 68 [5 suppl]: $211-214$

29. Wans LJ, Wong YC, Chen CJ and Lim KE: C-T features of genitourinay tuberculosis. J. Comput. Assist. Tomgr. 1997; 21: (2): $254-258$. 